\title{
Monitoring Electromagnetic Field Emitted by High Frequencies Home Utilities
}

\author{
Emanuele Calabrò, Salvatore Magazù
}

Department of Physics, University of Messina, Messina, Italy

Email: e.calabro@yahoo.com,smagazu@unime.it

Received June $5^{\text {th }}$, 2010; revised August 19 $9^{\text {th }}, 2010$; accepted August 26 $6^{\text {th }}, 2010$

\begin{abstract}
The aim of this study is to provide measurements of the electromagnetic field due to the 'electrosmog' emitted by some home electronic devices in the range of microwaves frequencies. The enormous increase in the use of mobile telephony throughout the world, microwave ovens, cordless phones and other high frequency home utilities suggests accurate measures of microwaves power density emitted by such devices to check that the exposure limits suggested by the International Commission on Non-Ionizing Radiation Protection are not exceeded. Measurements were carried out by a Narda SRM 3000. Spectrum analysis mode was chosen as a preliminary analysis to quantify the frequencies intensities of electromagnetic waves. Time analysis was successively conducted to operate selective and continuous measurements at a fixed frequency, allowing temporal check of power density and the related electromagnetic field components emitted by high frequencies home electronic devices.
\end{abstract}

Keywords: Electrosmog, Electromagnetic Field, Microwaves, High Frequency, Mobile Phone

\section{Introduction}

The achievement of electronics in all technological sectors and the growing demand for electric power have generated exposures of living beings to high frequencies electromagnetic field (HF-EMF).

Power lines, electric generators and motors, electric appliances, electronic devices and wireless communication systems generate electric and magnetic fields.

EMFs are produced everywhere in our homes, because of electrical wiring and very common devices such as electronic household appliances, mobile phone, microwave ovens, computers or television sets. Significant changes are afoot in the telecommunications sector, thanks to progress made in the new UMTS technologies, which allow the transmission of huge amounts of data on the airwaves and signal repeaters or mobile phone aerials.

All these technological environment produces a continuous electromagnetic waves emission, a phenomenon that has come to be known as 'electrosmog', a term coined in the 1970s. The part of the word 'smog' derives from the description of heavy industrial pollution where a mixture of smoke and fog produced horrendous clouds of air pollution in cities due to industrial processes. Elec- trosmog describes the dirt of electromagnetic pollution that is invisible and undetectable. It can be considered as the sum of all radiation coming from artificial sources in our environment.

The radiation produced by electrosmog can be broken down into different types.

Electrical fields are generated between two poles of opposite electrical potential. The closer these poles are to each other the stronger the field between them. It is not necessary for electrical current to flow in order to generate an electrical field because electric fields occur whenever a voltage difference occurs. Hence, any electrical device whether switched on or off will be a source of electrosmog. This is particularly true for cables hidden in walls and floors and therefore they represent a potential source of extremely low field (ELF) electromagnetic radiation.

Electric field component is usually not very strong in a building. High electric-field areas are found near TV or computer monitors, fluorescent lights or light dimmer controls and a safe distance from the field source is 1 meter at least. Electric fields are high near high-voltage power lines, but these fields rarely penetrate into a house.

In contrast, magnetic field component is much more common at home than electric field. Magnetic fields are 
generated when electricity flows through electrical conductors. Like electric fields, they produce current in the body. Most of the recent health concerns have been about magnetic fields.

The main sources of ELF magnetic fields are electrical appliances, power lines or underground power cables, transformers, motorized equipment, computers and any modern electronic equipment.

New wireless technologies produced the electromagnetic contamination as electrosmog in the ranges of radiofrequency (RF) and microwaves (MW) generated by HF-EMFs. RF frequency range occurs from $100 \mathrm{kHz}$ to $300 \mathrm{MHz}$, MW are at frequencies falling between 300 $\mathrm{MHz}$ and $30 \mathrm{GHz}$ on the electromagnetic spectrum. Almost all RF-MW radiation is man-made, produced by satellites, radar, radio, mobile phone, baby-phones, cordless telephones, bluetooth and more, in order to enable technical applications such as signals traveling over long distances.

HFs EMF can be produced either by nearby transmission towers or by central stations of mobile phones, while the field of a low frequency is mainly spread by the equipment in the home, as well as by electrical wiring.

Since 1970s, base stations for mobile telecommunication have been spreading across the urban centres, increasing the electromagnetic contamination in the RFMW range.

Mobile phone devices use electromagnetic radiation in the microwave range, at frequency bands usually close to 900 and $1800 \mathrm{MHz}$ that can interfere in the nervous system of organisms.

In spite of the great number of studies performed, knowledge about the adverse effects of RF and MW radiation on human health, or the biological responses to their exposure, is still limited [1,2].

Many scientific studies have investigated possible health effects of mobile phone radiations. An assessment published in 2007 by the European Commission Scientific Committee on Emerging and Newly Identified Health Risks (SCENIHR) concluded that no significant health effect has been demonstrated from mobile phone radiation at normal exposure levels. However, more studies concerning potential health effects on children are needed [3].

Some scientific studies focused on the danger of MW radiation for health in humans and animals [4]. It was demonstrate that animals exposed to RF-MW field in the vicinity of transmitting antennas show conspicuous abnormalities [5,6].

It was found that RF-MW radiations produce a response in many types of neurons in the avian Central Nervous System [7]. MW radiation emitted by mobile phones can affect central cholinergic activity in the rat [8] and their learning memory tasks [9]. Furthermore, effects on blood-brain barrier permeability [10,11] and oxidative damage in brains tissues [12] were observed.

Karinen et al. [13] demonstrated that protein expression in human skin can be affected by the exposure to RF-EMF. Calabrò et al. [14] observed changes in heat-shock proteins expression of human neuronal-like cells exposed to MW radiations. In addition, several studies proved that the exposure to RF-MW radiation can alter DNA and gene structures [15-17].

In view of previously effects of RF-MW radiations, various authorities have long defined limit values to protect people from excessive exposure.

National radiation advisory authorities have recommended measures to minimize exposure to their citizens, following the Guidelines for exposure limits to electromagnetic fields of the International Commission on Non-Ionizing Radiation Protection (I.C.N.I.R.P.) [18].

However, it becomes necessary to avoid overexposure to electromagnetic waves and to make sure that installations are carefully and regularly monitored. Hence accurate measures need for monitoring power density and EMF emitted by the most used electronic devices in our home, particularly those emitting RF-MW radiations.

\section{Materials and Methods}

The value of electrosmog is generally measured by means of monitoring stations located in the vicinity of or inside the critical zones. The instrument used is available not only to the cantonal or local council authorities, but also to the population.

Electrosmog-meter-detector such as Gaussmeter, Teslameter, ELF-meter, are needed to measure the level of ELF-EMF produced by power lines, computers, TVs, kitchen appliances, enabling to find hidden sources of ELF frequency magnetic fields, and determining the effectiveness of eventual electric shielding devices.

HF-meter/detector can be used to measure the electromagnetic field emitted by high frequency appliances and devices.

A SRM-3000 instrument of Narda Safety Test Solutions was chosen to measure the electromagnetic field components related to three typical high frequency home utilities. Narda SRM 3000 frequency range can vary from $100 \mathrm{kHz}$ to $3 \mathrm{GHz}$. It was linked through a cable to a Narda three axis antenna covering the frequency range from $75 \mathrm{MHz}$ to $3 \mathrm{GHz}$, determining the three spatial components of the EMF being measured.

The "Spectrum Analysis" mode of the device was chosen as preliminary analysis. This function enables to detect and quantify the frequencies values relative to the electromagnetic waves impinging the three axis antenna. Hence, in Spectrum Analysis mode all the field compo- 
nents in the environment can be detected and measured. The frequency range in Spectrum Analysis can be set by entering the upper and lower frequencies. Spectra analysis represented in Figure 1 and Figure 3 were carried out by setting a narrow frequency range so that the maximum number of frequencies can be detected.

Otherwise, only signals which are separated by a frequency greater than the defined resolution bandwidth (RBW) can be distinguished from one another. Hence the RBW characterizes the selectivity of the spectrum analyzer in respect of signals having the same amplitude.

The SRM-3000 can automatically define a suitable RBW, depending on the selected frequency span. This function gave the value $\mathrm{RBW}=6 \mathrm{MHz}$ for the spectral analysis shown in Figure 1 and Figure 3.

The Average Mode was chosen as result type, and the average of the measured values were taken over a number of 16 results.

In "Time Analysis" mode, the device can provide selective and continuous measurements at a fixed frequency, allowing temporal check of power density of radiation. In addition the intensities of the related electric and magnetic field components can be monitored. This operating mode is ideal for timer-controlled measurements since the instrument mode enables one to carry out selective measurements at a defined frequency, to monitor the EMF level at the selected channel.

This operating mode function produces that RBW can be selected to match the channel bandwidth, averaging over a user defined time period, e.g. 6 minutes. Better results were obtained at $\mathrm{RBW}=5 \mathrm{MHz}$.

Spectrum and Time analysis results were transferred to a PC for monitoring the electromagnetic components related to the RF-MW emitted during some conversations by mobile phones and cordless telephones, and during microwave ovens working.

Mobile phones, microwave ovens and cordless telephones have been considered the most representative home electronic utilities emitting in the range of MW radiation.

The mobile phones Nokia 1208, LG model U8330, Motorola V635, the microwave ovens Whirlpool Model AVM 541/WP/WH, Termozeta MW 250 D, Samsung CE 137, and the cordless telephones Brondi DC3010, Siemens Gigaset $\mathrm{A} 38 \mathrm{H}$, were used to measure MW radiation emitted during their working.

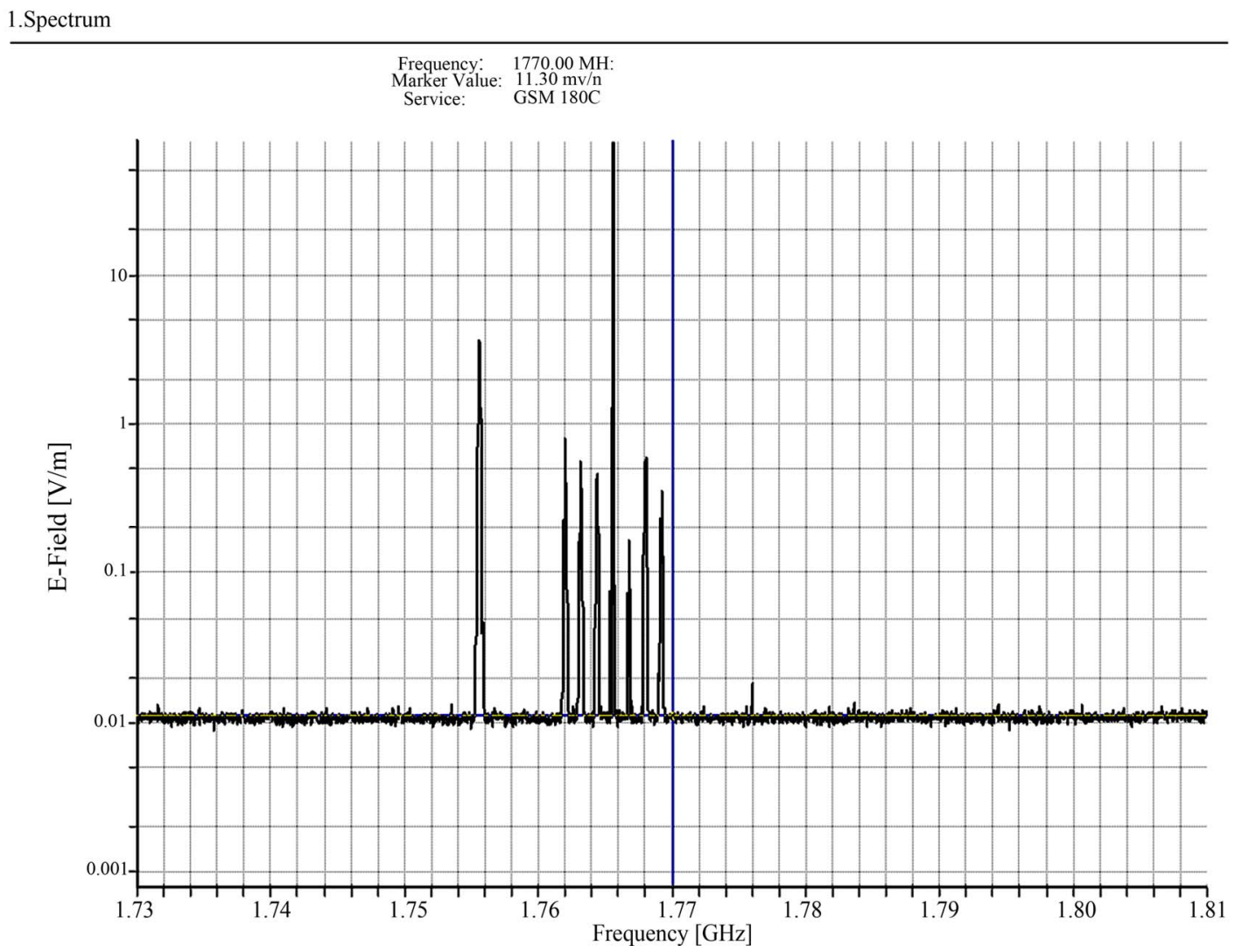

Figure 1. A representative spectrum analysis of the electric field component measured by Narda SRM 3000 at $2 \mathrm{~cm}$ from a mobile phone Nokia 1208 during a conversation. The limit of $59 \mathrm{~V} / \mathrm{m}$ suggest by the ICNIRP for the electric component was exceeded at $1766 \mathrm{MHz}$. 
1.Value

Value: $42.11 \mathrm{~mA} / \mathrm{m}$

2.IIistory

$\begin{array}{rrr}\text { HistTime: } & 11: 24: 49.0 \text { Time: } & 11: 24: 49.0 \\ \text { HistValuee: } & 42.11 \mathrm{~mA} / \mathrm{m} \text { Value: } & 42.11 \mathrm{~mA} / \mathrm{m}\end{array}$

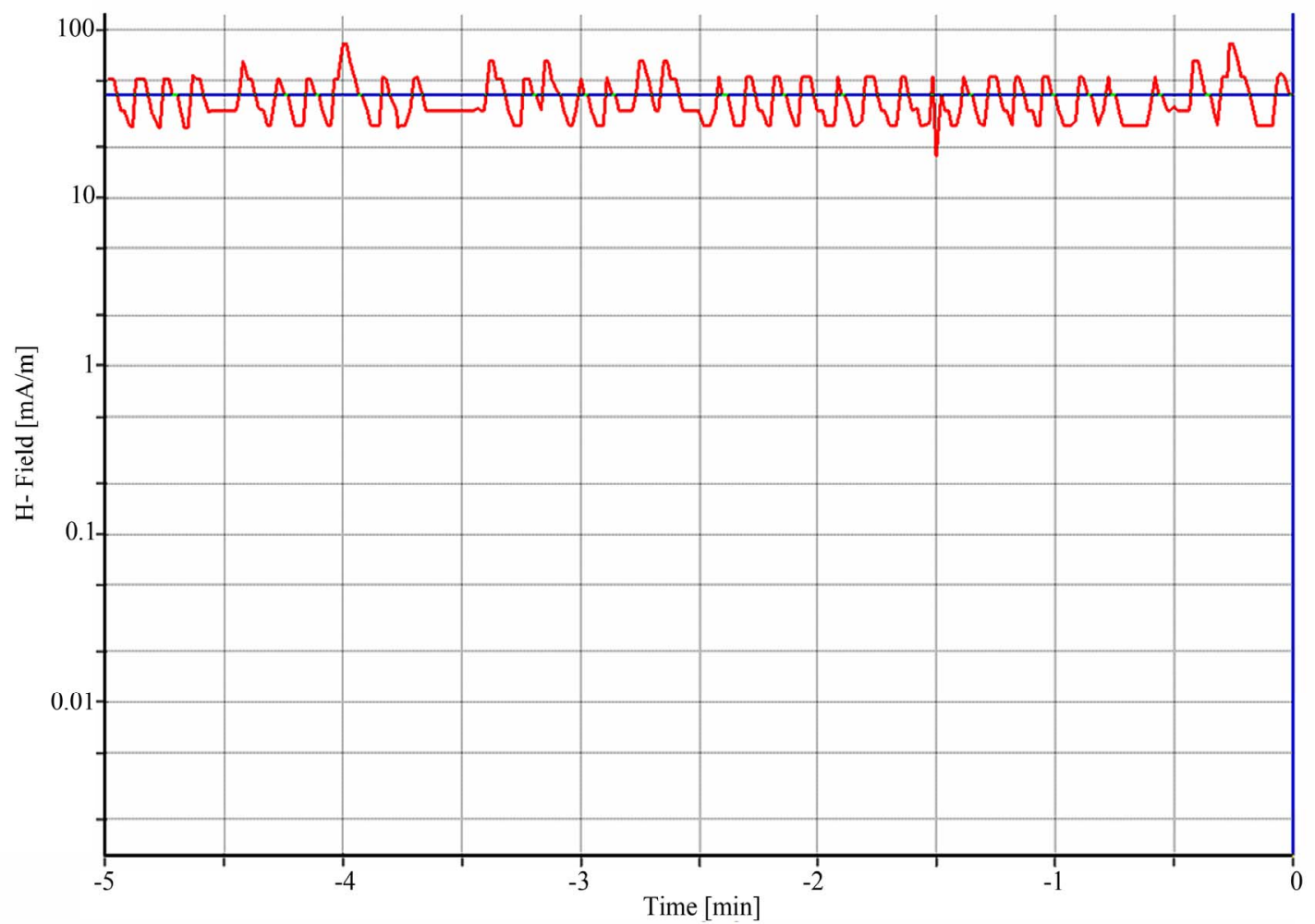

Figure 2. A typical time analysis of the magnetic field component measured by Narda SRM 3000 at $2 \mathrm{~cm}$ from a mobile phone Nokia 1208, with respect to a frequency centred at $1757 \mathrm{MHz}$ during an exposure.

\section{Results and Discussion}

A typical house consists of a matrix of wires throughout the walls and ceilings. Moreover home devices or appliances are particularly MW sources, above all mobile phones and transmission masts, Wi-Fi systems and cordless phones.

First, we must differentiate between thermal and non-thermal effect of RF-MW radiations.

Whereas electric currents flow inside the body when ELF is concerned, the radiated energy within the body in $\mathrm{HF}$ fields is mainly transformed into heat, and the temperature increase in the organism can cause damage.

The unit used to measure it is the Specific Absorption Rate (SAR) which is given in watts per kilogram and its maximum levels for modern handsets have been set by governmental regulating agencies. In the USA a SAR limit of $1.6 \mathrm{~W} / \mathrm{kg}$ has been assigned, averaged over a volume of 1 gram of tissue, for the head. In Europe, the limit is $2 \mathrm{~W} / \mathrm{kg}$, averaged over a volume of 10 grams of tissue.

Second, it must be taken into account that besides the thermal effect, the so-called "non-thermal effect" of the fields can have a negative influence on the biological system, an effect which can occur even when the radiation emission is extremely low. Persons working in MW fields have reported headaches, eyestrain, over-all fatigue and disturbance of sleep. These effects have been associated with the interaction of the MW fields with the central nervous system of the body. Such effects have been labeled as "non-thermal" interactions. These may be responsible for some of the long-term effects from prolonged exposure to low levels of EMFs. There is no confirmed scientific evidence to prove a link between such effects and MW exposure. However, accurate monitoring need to check that exposure limits recommended by I.C.N.I.R.P., at least, are not exceeded.

Results reported here strictly depend on the local base station to which mobile phone signal was transmitted. In 
fact, when a user of a mobile phone makes a call, it is transmitted to the nearest base station, which receives and transmits radio signals in its area. The area covered by a base station is called a "cell". The number of cells varies in different areas, depending on the volume of use. Areas with a high volume of mobile phone use will have more cells, and as the phone user moves around, the radio signal can be switched from one cell to another, maintaining a good connection.

The total power output of a typical mobile phone base station depends on the type of antenna, the number of analog and digital channels that operate at a given time and at their maximum strength, and the antenna gain which gives the signals direction and strength. In addition, the power level generated by a mobile phone to maintain a good connection depends on the distance from the base station: more power is needed for great distances from the base station within a cell.

The power output is less when the base station is close to the phone user. Hence, base stations are being placed closer together, to make it simpler for a phone and a base station to communicate reliably and to minimize the power output of a mobile phone.

This fact suggests particular checks of power level during cellular phone calls in areas with a low volume of use, because a great distance from the base station could increase the power output of a typical mobile phone working.

Measurements were carried out in South-Italy to check that the power density at 1-2 centimetres from some cellular phones was lesser than $9 \mathrm{~W} / \mathrm{m}^{2}$ (resulting from the expression $\mathrm{f} / 200$ as to the frequency of $1800 \mathrm{MHz}$ ) in line with the Guidelines for public exposure limits to electromagnetic fields [18].

Analogue checks were performed with respect to the electric and magnetic components of the electromagnetic field.

The magnetic field component $\mathrm{H}$ should be lesser than $111 \mathrm{~mA} / \mathrm{m}$ (as to $900 \mathrm{MHz}$ band) and $159 \mathrm{~mA} / \mathrm{m}$ (as to $1800 \mathrm{MHz}$ band), resulting from the expression $\mathrm{H}<$ $0.0037 \mathrm{f}^{1} / 2\left(\mathrm{Am}^{-1}\right)$ reported on Table 7 of the mentioned Guidelines. Finally, the intensity of the electric field component $\mathrm{E}$ must not exceed the limit of $59 \mathrm{~V} / \mathrm{m}$ resulting from the expression $E<1.375 f 1 / 2$ [18].

Several measures were performed by spectrum analysis mode of Narda SRM 3000 to find the exact frequency values where the highest peaks occur during a call, connecting with local phone networks such as Vodafone or Wind. A representative spectrum analysis of the electric field component measured at $2 \mathrm{~cm}$ from a mobile phone Nokia 1208 during a call is shown in Figure 1.

Figure 1 shows as the radiation emitted by a mobile phone working consists of a number of peaks at different frequencies close to $1800 \mathrm{MHz}$, whose intensities change continuously during the conversation, due to the continuous connections to the local base station as above specified. In particular, the spectrum represented in Figure 1 shows that the limit of $59 \mathrm{~V} / \mathrm{m}$ for the electric component was exceeded at the frequency of $1766 \mathrm{MHz}$ during a measurement. Nevertheless the peak intensities of EMF frequencies change continuously during mobile phone working, as it can be observed by time analysis mode.

A typical time analysis of the magnetic field component due to the MWs emitted by the same mobile phone during a conversation is represented in Figure 2 with respect to a frequency centred at $1757 \mathrm{MHz}$, where appeared that the limit of $159 \mathrm{~mA} / \mathrm{m}$ was not exceeded during an exposure of 5 minutes at that fixed frequency.

Microwave oven is another common device often used at home. The source of the radiation in a microwave oven is the magnetron tube, which converts powerline electric current to electromagnetic radiation around $2450 \mathrm{MHz}$.

The high voltage (about 3,000 or 4,000 volt) which powers the magnetron tube is produced by a step-up transformer rectifier, and filter which converts the AC of line voltage to $4 \mathrm{kV}$ DC.

The microwave energy from the magnetron is transferred to the oven cavity through a waveguide section. Heat is produced when the water molecules in the food vibrate (at a rate of 2,450,000,000 times per second) when the food absorbs the microwave radiation. The movement of the molecules produce friction which causes heat.

Microwave ovens are heavily shielded to stop leakage and shut off automatically if the door is opened. Nonetheless, microwave ovens use a lot of grid electricity and produce high levels of power frequency EMF as much as $200 \mathrm{mG}$ at 50 centimeters.

Typical levels of radiation leakage from microwave ovens is about $0.2 \mathrm{~mW} / \mathrm{cm}^{2}$.

A spectrum analysis was acquired at $30 \mathrm{~cm}$ from the door of a working Whirlpool AVM 541/WP/WH. Spectrum analysis of the electric component was represented in Figure 3(a), in which a maximum appears around $2470 \mathrm{MHz}$ within a range of exposure from 2400 to 2480 MHz. Spectrum analysis of magnetic component was represented in Figure 3(b), as well. Such results showed that electric and magnetic components related to the MW radiation do not reach high values during microwave ovens working, as confirmed by other measurements carried out on the microwave ovens devices listed in section 2.

Furthermore, the relative measured power frequency electromagnetic field was lesser than $100 \mathrm{~mW} / \mathrm{m}^{2}$, as shown in Figure 4 at the same exposure conditions. 


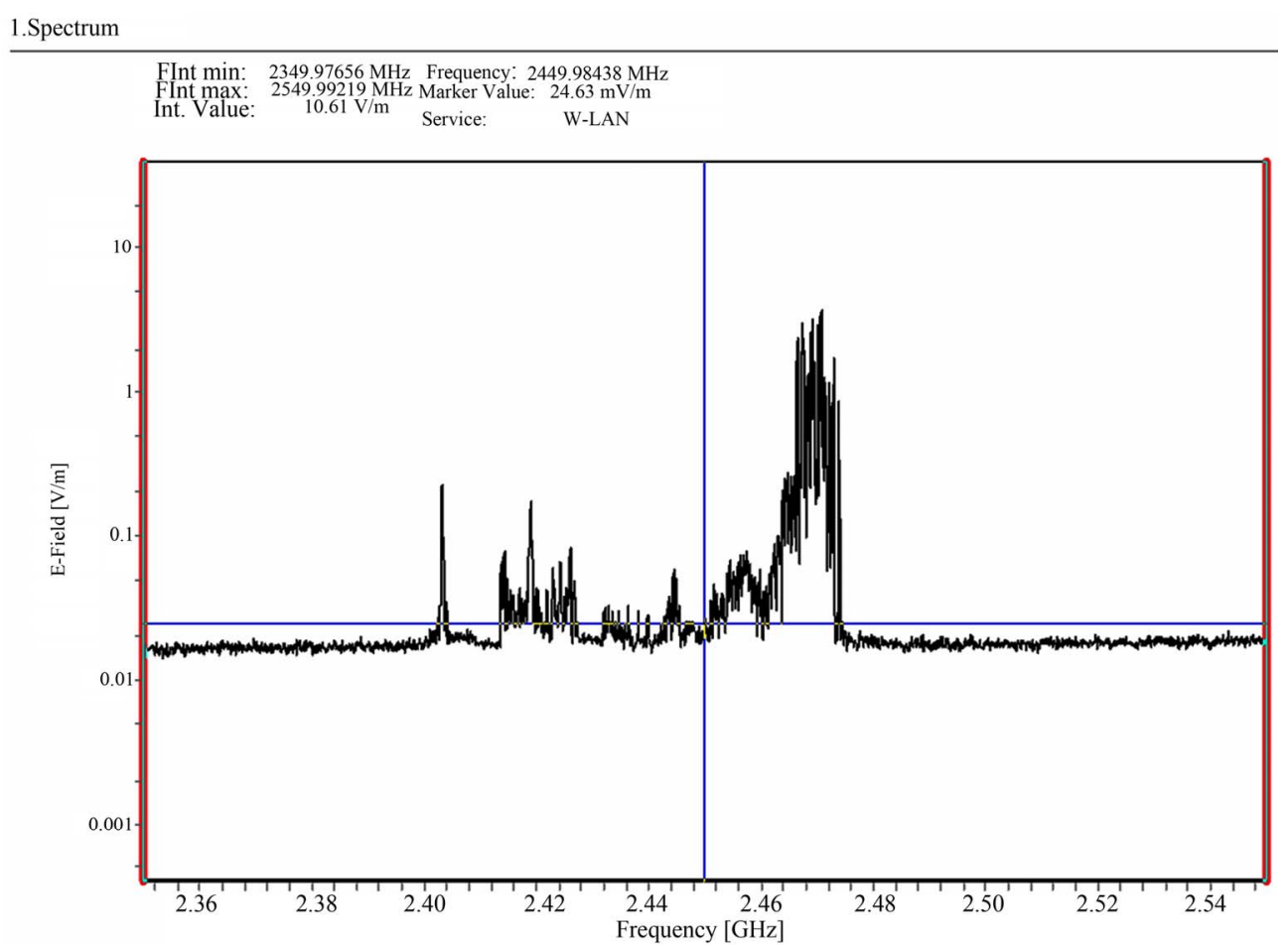

(a)

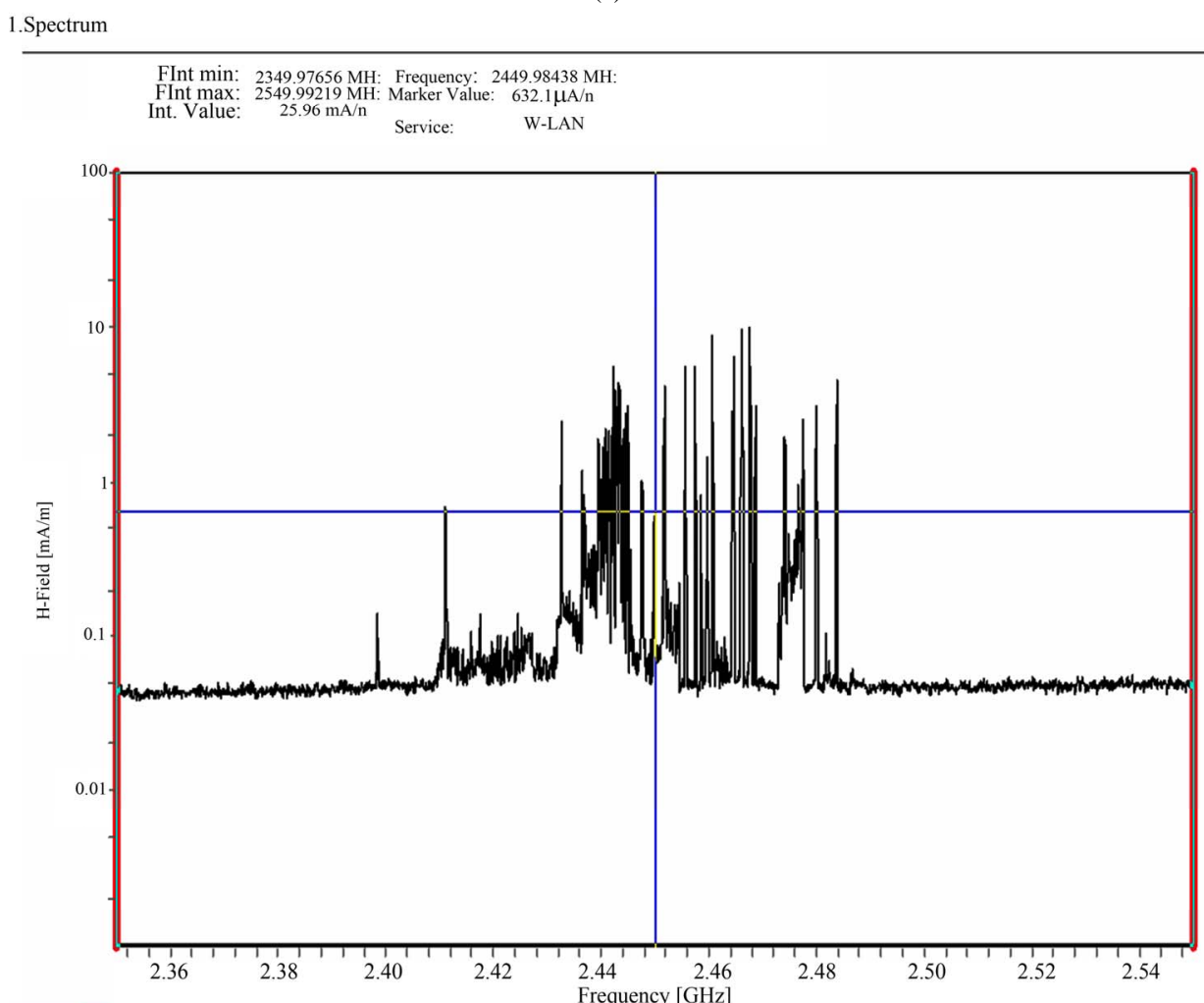

(b)

Figure 3. (a) A representative spectrum analysis performed by Narda SRM 3000 in the range of $2400-2500 \mathrm{MHz}$ of the electric component related to MW radiations generated by a working microwave oven Whirlpool Model AVM 541/WP/WH, acquired at $30 \mathrm{~cm}$ from the door's device; (b) Spectrum analysis of the magnetic component emitted by a microwave oven Whirlpool Model AVM 541/WP/WH at the same exposure conditions illustrated for Figure 3(a). 


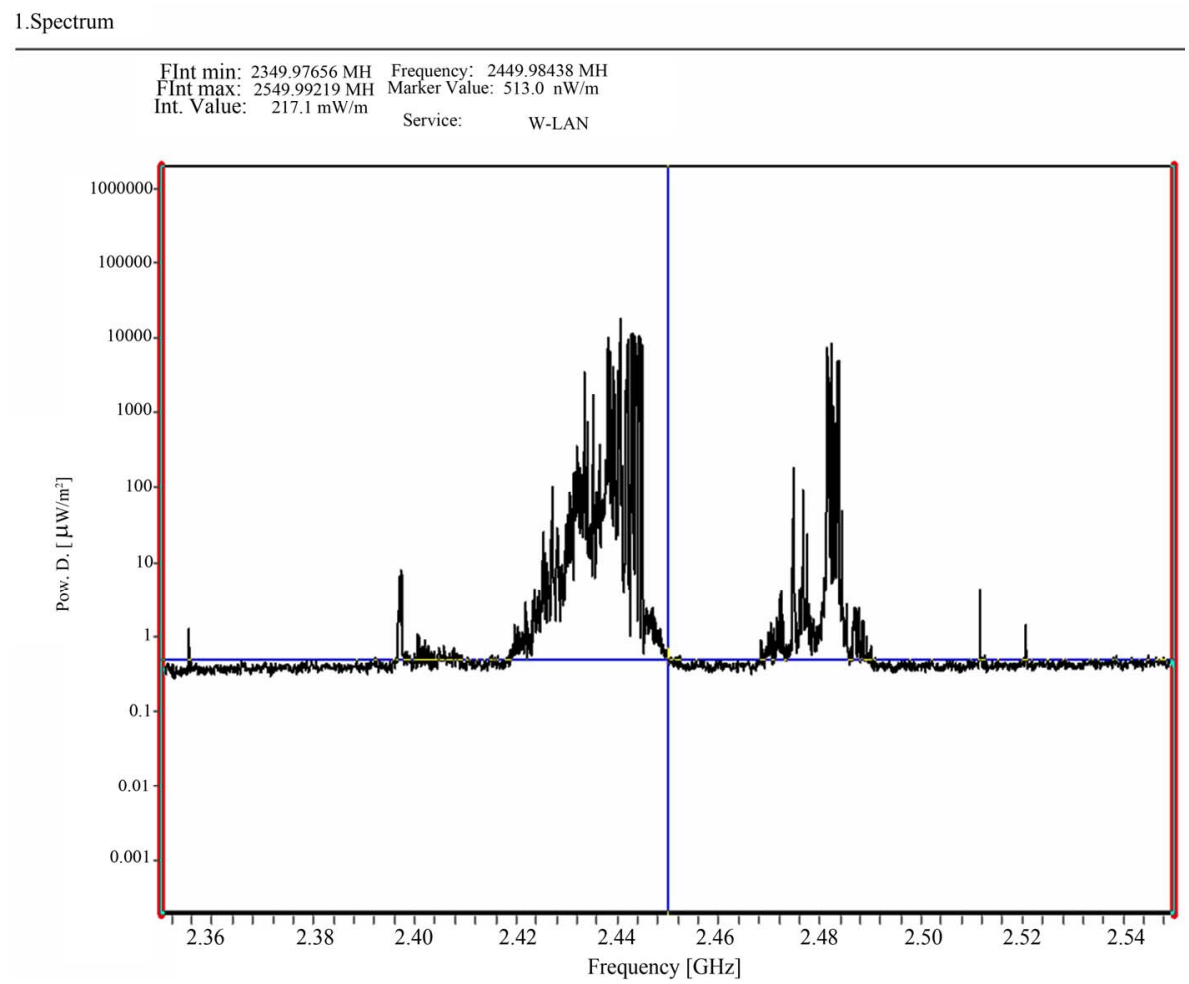

Figure 4. A typical spectrum analysis of the relative power density emitted by a microwave oven Whirlpool Model AVM 541/WP/WH, measured at the same exposure conditions indicated for Figure 3(a) and Figure 3(b).

Some standards applied to microwave ovens sets safe exposure limits as follows.

In U.S.A. the ANSI/IEEE-C95.1-1991 stated that the power density of a microwave oven should not exceed $1.6 \mathrm{~mW} / \mathrm{cm}^{2}$ at $2450 \mathrm{MHz}$ for human exposure in uncontrolled environments.

Otherwise the IRPA (International Radiation Protection Association) Guidelines recommends exposure limit of $5 \mathrm{~mW} / \mathrm{cm}^{2}$ for RF workers and $1 \mathrm{~mW} / \mathrm{cm}^{2}$ for the general public. These exposure limits are averaged over 6 minutes period.

Regarding cordless telephone system the handset is not wired to its base unit, but wireless communication techniques between a remote handset and its base unit is used, permitting a user to move freely and not be physically restricted by a telephone cord.

The base unit provides a wireless connection to a handset. The handset is capable of receiving and transmitting signals over a wireless link to the base unit. The handset can be removed from the base unit and used within a predetermined range, which is limited by the RF signal strength and not cord length. Cordless telephones typically operate over a RF portion of the spectrum set aside for general public use. The frequency band is broken up into a number of channels that may be used by the handset and base station. Only a relatively small portion of the radio spectrum has been allocated to cordless telephones and these telephones operate on a selected band of a relatively few channels, as can be observed in Figures 5(a),(b).

The RF link either transmits the voice signals between the base unit and the remote handset using frequency modulation techniques or using digital techniques such as quadrature amplitude modulation or frequency shift keying. The RF link between the handset and the base unit is typically divided into two portions, such as an uplink from the handset to the base unit at a first frequency, and a downlink from the base unit to the handset at a second frequency.

DECT base stations transmit signals permanently, 24 hours a day, even when the phone is not being used. The small installation works just like a big one with pulsed radio signals, pulsed at $100 \mathrm{~Hz}$ in the low frequency range and high-performance in the HF typical range between 1800 and $1900 \mathrm{MHz}$. Spectral analysis of power density and magnetic component of MW emitted by the model Brondi DC3010 are shown in Figure 5(a) and Figure 5(b), respectively.

It was verified that the limit of [18] was not exceeded and that the exposure occurs within a narrow frequency range from 1880 and $1890 \mathrm{MHz}$.

The increase of temperature in cordless devices is gene- 


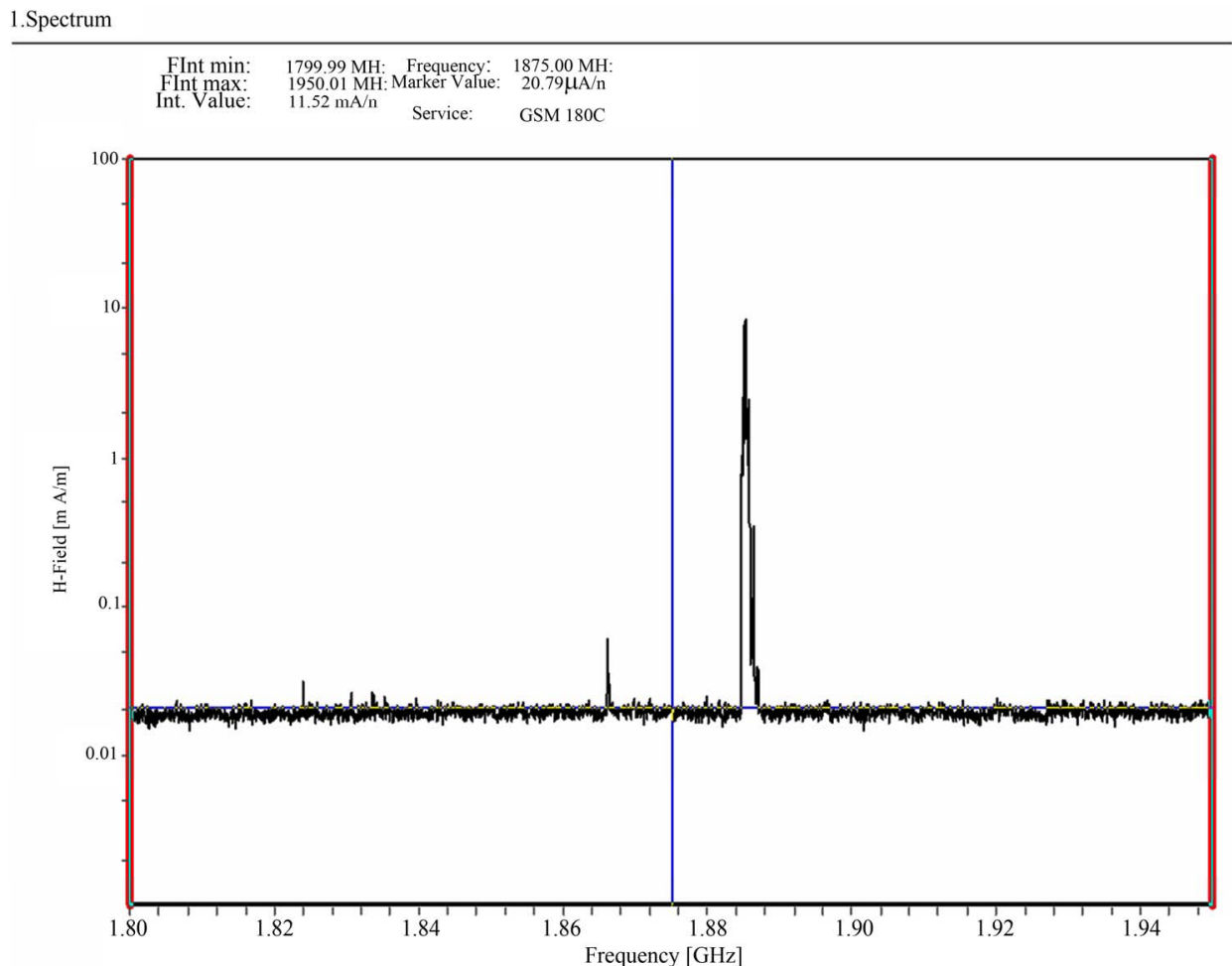

(a)

1.Spectrum

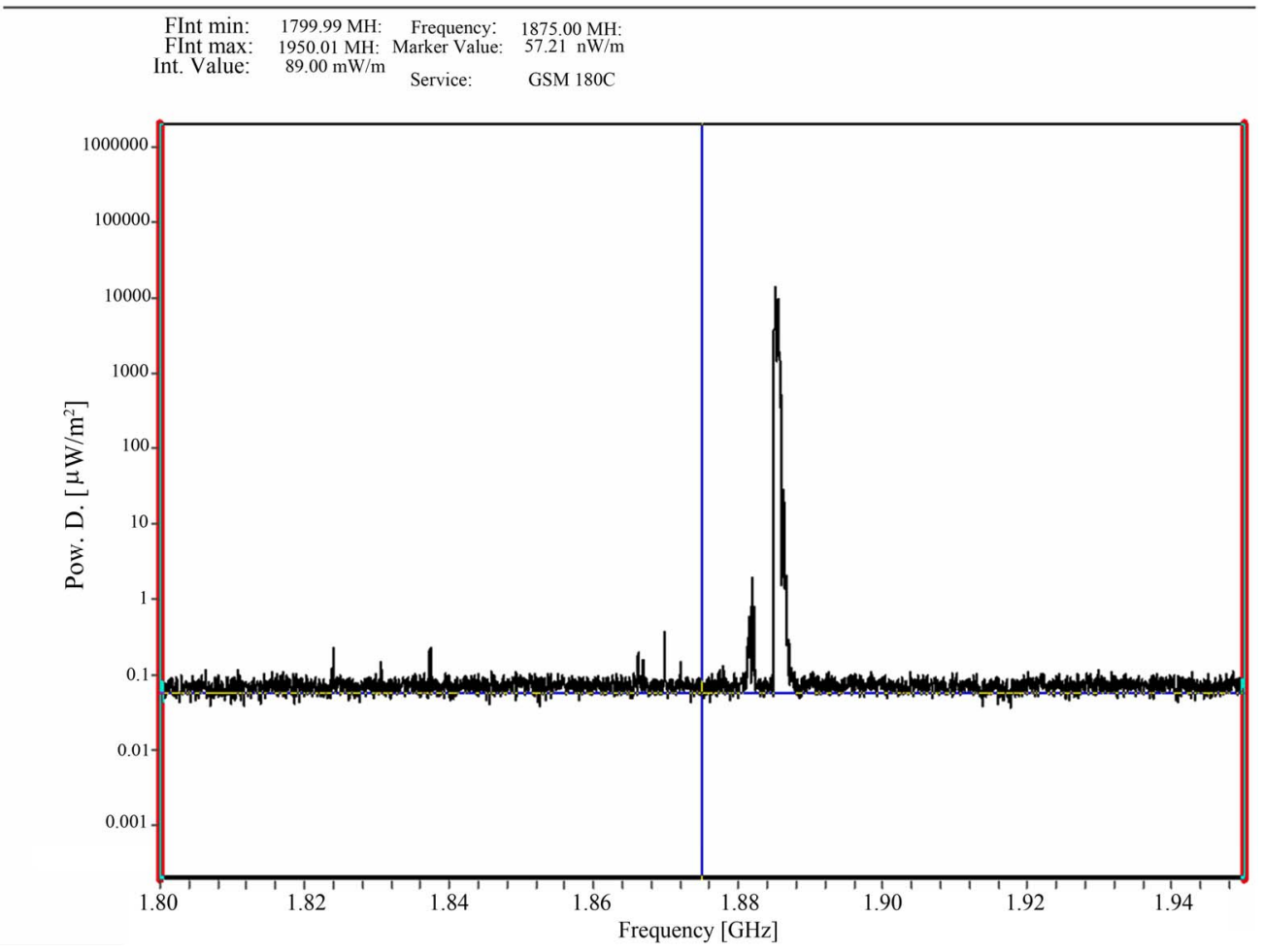

(b)

Figure 5. (a) A typical spectrum analysis of magnetic component of microwaves emitted by a cordless Brondi DC3010, acquired by Narda SRM 3000. (b) A typical spectrum analysis of power density of microwaves emitted by a cordless Brondi DC3010, acquired by Narda SRM 3000. 
rally lesser than that produced by mobile phones batteries. This may be wrongly interpreted by users as a lack of warning about eventual long-term effects on health.

\section{Conclusions}

This brief study has provided measuring methods to quantify high frequency electromagnetic radiation levels coming from artificial sources in a typical house. Spectrum and time analysis modes performed on mobile phones microwaves showed that the limits recommended by the I.C.N.I.R.P. can be exceeded during a conversation, depending on the distance of the user from the local base station. Analogue measures relative to high frequencies radiations of some cordless telephones evidenced microwave radiation emissions in a narrow band close to $1900 \mathrm{MHz}$, within those suggested exposure limits. Spectrum analysis performed on some working microwave ovens showed a large frequency range exposure from 2400 to $2500 \mathrm{MHz}$, not exceeding the limits recommended by some international guidelines. Nevertheless such result can not be considered negligible. Our measurements and other previous studies performed so far suggest to monitor RF-MW intensities in our living environment. However, further research is needed to find reliable protective effectiveness relative to high frequencies home devices.

\section{REFERENCES}

[1] T. Q. Huang, M. S. Lee, E. Oh, B. T. Zhang, J. S. Seo and W. Y. Park, "Molecular Responses of Jurkat T-Cells to 1763 MHz Radiofrequency Radiation,” International Journal of Radiation Biology, Vol. 84, No. 9, 2008, pp. 734741.

[2] K. Makker, A. Varghese, N. R. Desai, R. Mouradi and A. Agarwal, “Cell Phones: Modern Man's Nemesis?” Reproductive Biomedicine Online, Vol. 18, No. 1, 2009, pp. 148-157.

[3] Scientific Committee on Emerging and Newly Identified Health Risks (SCENIHR), "Possible Effects of Electromagnetic Fields (EMF) on Human Health,” 21 March 2007.

[4] G. J. Hyland, "Physics and Biology of Mobile Telephony," The Lancet, Vol. 356, No. 9244, 2000, pp. 1-8.

[5] T. A. Marks, C. C. Ratke and W. O. English, "Strai voltage and Developmental, Reproductive and Other Toxicology Problems in Dogs, Cats and Cows: A Discussion,” Vet Hum Toxicol, Vol. 37, No. 2, 1995, pp. 163-172.

[6] W. Löscher and G. Käs, “Conspicuous Behavioural Abnormalities in a Dairy Cow Herd near a TV and Radio Transmitting Antenna," Practical Veterinary surgeon, Vol. 29, No. 5, 1998, pp. 437-444.

[7] R. C. Beasond and P. Semm, "Responses of Neurons to an Amplitude Modulated Microwave Stimulus," Neuroscience Letters, Vol. 333, No. 3, 2002, pp. 175-178.

[8] H. Lai , A. Horita, C. K. Chou and A. W. Guy, "Lowlevel Microwave Irradiation Affects Central Cholinergic Activity in the Rat," J. Neurochem. Vol. 48, 1987, pp. 40-45

[9] G. Thuroczy, I. Hernadj and L. Kelleny, "Activity and Learning Memory Task of the Rat,” Bioelectromagnetics, Vol. 27, 2001.

[10] K. Fritze, C. Sommer, B. Schmitz, G. Mies, K. Hossman, M. Kiessling et al., "Effect of Global System for Mobile Communication (GSM) Microwave Exposure on BloodBrain Barrier Permeability in Rat," Acta Neuropathol (Berlin), Vol. 94, No. 5, 1997, pp. 465-470.

[11] F. Töre, P. E. Dulou, E. Haro, B. Veyret and P. Aubineau, "Two-hour Exposure to 2 W/kg, 900 MHz GSM Microwaves Induces Plasma Protein Extravasation in Rat Brain,” In: Proceedings from the 5th Int. Congress of the European Bioelectromagnetics Association, 6 September 2001. Finnish Institute of Occupational Health, Helsinki , 2001, pp. 43-45.

[12] L. G. Salford, A. E. Brun, J. L. Eberhardt, L. Malmgren and B. R. Persson, "Nerve Cell Damage in Mammalian Brain after Exposure to Microwaves from GSM Mobile Phones," Environmental Health Perspectives, Vol. 111, No. 7, 2003, pp. 881-883.

[13] A. Karinen, S. Heinävaara, R. Nylund and D. Leszczynski, "Mobile Phone Radiation Might Alter Protein Expression in Human Skin,” BMC Genomics, 2008.

[14] E. Calabrò, S. Condello, M. Currò, N. Ferlazzo, D. Caccamo, S. Magazù and R. Ientile, "Modulation of HSP Response in SH-SY5Y Cells Following Exposure to Microwaves of a Mobile Phone,” submitted, 2010.

[15] I. Y. Belyaev, C.B. Koch, O. Terenius, K. RoxstromLindquist, L.O. Malmgren, W.H. Sommer, L.G. Salford and B.R. Persson, "Exposure of Rat Brain to $915 \mathrm{MHz}$ GSM Microwaves Induces Changes in Gene Expression but not Double Stranded DNA Breaks or Effects on Chromatin Conformation,” Bioelectromagnetics, Vol. 27, No. 4, 2006, pp. 295-306.

[16] E. Diem, C. Schwarz, F. Adlkofer, O. Jahn and H. Rudiger, "Non-thermal DNA Breakage by Mobile-Phone Radiation (1800MHz) in Human Fibroblasts and in Transformed GFSH-R17 Rat Granulosa Cells in vitro," Mutation Research, Vol. 583, No. 2, 2005, pp. 178-183.

[17] R. R. Tice, G. G. Hook, M. Donner, D. I. McRee and A. W. Guy, "Genotoxicity of Radiofrequency Signals. Investigation of DNA Damage and Micronuclei Induction in Cultured Human Blood Cells,” Bioelectromagnetics, Vol. 23, No. 2, 2002, pp. 113-126.

[18] International Commission on Non-Ionizing Radiation Protection, "Guidelines for Limiting Exposure to TimeVarying Electric, Magnetic, and Electromagnetic Fields (up to $300 \mathrm{GHz}$ )," Health Physics, Vol. 74, No. 4, 1998, pp. 494-522. 